\title{
Prediction of Melting Point for Drug-like Compounds Using Principal Component-Genetic Algorithm-Artificial Neural Network
}

\author{
Aziz Habibi-Yangjeh, Eslam Pourbasheer, and Mohammad Danandeh-Jenagharad \\ Department of Chemistry, Faculty of Science, Lnwersity of Hohaghegh Ardabili, P. O. Box 179, Ardabil, Iran \\ "E-mail: ahabibianma.ac.ir \\ Received December 9, 2007
}

\begin{abstract}
Principal component-genetic algorithm-multiparameter linear regression (PC-GA-MLR) and principal component-genetic algorithm-artificial neџral network (PC-GA-ANN) models were applied for prediction of melting point for 323 drug-like compounds. A large number of theoretical descriptors were calculated for each compound. The first $23+$ principal components ( $\mathrm{PC}^{\prime}$ 's) were found to explain more than $99.9 \%$ of variances in the original data matrix. From the pool of these PC's. the genetic algoritlum was employed for selection of the best set of extracted PC's for PC-MLR and PC-ANN models. The models were generated using fifteen PC's as variables. For evaluation of the predictive power of the models. melting points of 64 compounds in the prediction set were calculated. Root-mean square errors (RMSE) for PC-GA-MLR and PC-GA-ANN models are 48.18 and $12.77^{\circ} \mathrm{C}$. respectively. Comparison of the results obtained by the models reveals superiority of the PC-GA-ANN relative to the PC-GA-MLR and the recently proposed models (RMSE $=40.7^{\circ} \mathrm{C}$ ). The improvements are due to the fact that the melting point of the compounds demonstrates non-linear correlations with the principal components.
\end{abstract}

Key Words : Quantitative structure-property relationship. Melting point. Drug-like conpounds. Genetic algoritlim. Artificial neural network

\section{Introduction}

Melting point is a fundamental physical property of organic compounds. which has found wide use in chemical identification. as a criterion of purity and for the calculation of other important physicochemical properties such as vapor pressure and aqueous solubility. 2 The solubility of a compound in water is strongly correlated with its melting point. An estimate of the water-solubility of a compound before it is synthesized. or available in sufficient purity for analytical measurements. would be most useful. ${ }^{3}$ Adequate aqueous solubility is necessary for a compound to be transported to the active site within an organism. As noted above. melting point affects solubility. and solubility controls toxicity in that. if a compound is only poorly soluble. its concentration in the aqueous enviromment may be too low for it to exert a toxic effect. ${ }^{4.5}$ Thus, it would be helpful to be able to estimate the melting point of a compound from its chemical structure. ${ }^{6.7}$ Prediction methods for melting point. mainly can be categorized as property-property relationship (PPR). group contribution. and quantitative structure-property relationship (QSPR) ${ }^{8.5}$ Comprehensive reviews of the subject reveal that many studies involved hydrocarbons and homologous compounds. ${ }^{1612}$ This is because of the difficulty of melting point prediction for various organic compounds. since the numerous factors that control it are not easy to quantify.

The prediction of physicochemical and biological properties/ activities of organic molecules are the main objective of quantitative structure-property/activity relationships (QSPRs/ QSARs). The QSPR/QSAR models now correlate chemical structure to a wide variety of physical, chemical. biological (including biomedical. toxicological. ecotoxicological) and technological properties. ${ }^{13-17}$ QSPR/QSAR models are obtained on the basis of the correlation between the experimental values of the property/activity and descriptors reflecting the molecular structure of the compounds. To obtain a significant correlation. it is crucial that appropriate descriptors be employed. A wide variety of molecular descriptors has been reported for using in QSPR/QSAR models. ${ }^{18}$ However as the number of descriptors (variables) increases. the model becomes complicated and its interpretation is difficult if many variables are used in modeling. Therefore. the application of these teclniques usually requires variable selection for building well-fitted models. A better predictive model can be obtained by ortogonalization of the variables by means of principal component analy sis (PCA) ${ }^{19.21}$ The principal component analysis was used to compress the descriptor groups into principal components (PC's). In order to reduce the dimensionality of the independent variable space. a limited number of PC's are used." Hence. selecting the significant and informative PC's is the main problem in all of the PCA-based calibration methods. ${ }^{2-25}$ Different methods have been addressed to select the significant PC's for calibration purposes. The simplest and most conmon one is a top-down variable selection where the $\mathrm{PC}$ 's are ranked in the order of decreasing eigenvalues and the $\mathrm{PC}$ 's with highest eigenvalue is considered as the most significant one and. subsequently. the PC's are introduced into the calibration model. However. the magnitude of an eigenvalue is not necessarily a measure of its significance for the calibration. ${ }^{25}$ In the other method. 
which is called correlation ranking. the PC's are ranked by their correlation coefficient with the property and selected by the procedure discussed for eigenvalue ranking. ${ }^{.1 .23}$ Better results are often achieved by this method. Recently. genetic algorithm (GA) has been applied for the selection of the most relevant PC's instead of the older methods. Comparison of the results obtained using GA principal component selection with the two above-mentioned methods shows that GA gives a better result and close to the correlation ranking ${ }^{20.28} \mathrm{GA}$ is a stochastic method to solve optinization problems applying evolution hypothesis of Danwin and different genetic functions. i.e. cross-over and mutation ${ }^{29.30}$ Genetic algorithm is robust. global and generally more straightforvard to apply in situations where there is little or no a priori hnowledge about the process to be controlled. ${ }^{\text {t9 }}$

Artificial neural networks (ANNs) have become popular in QSPR/QSAR models due to their success where complex non-linear relationships exist amongst data. ${ }^{31.32}$ An ANN is formed from artificial neuron. connected with coefficients (weights), which constitute the neural structure and are organized in layers. The layers of neurons between the input and output layers are called hidden layers. Neural networks do not need explicit formulation of the mathematical or physical relationships of the handled problem. These give ANNs an advantage over traditional fitting methods for some chenical applications. For these reasons in recent years. ANNs have been applied to a wide variety of chemical problemts. $\hat{3 \hat{j} \cdot 4 \hat{2}}$

Very recently, QSPR models have been applied for prediction of the melting point of 323 set of drug-like compounds. ${ }^{\text {ts }}$ Ability of these models for prediction of the melting point is poor (for example, root-mean square error of the models is approxinately $40.7^{\circ} \mathrm{C}$ ). In order to predict accurately melting point of the same compounds. in the present work, principal component-genetic algorithm-multiparameter linear regression (PC-GA-MLR) and principal component-genetic algoritlun-artificial neural network (PCGA-ANN) models were employed to generate QSPR models between the principal components and melting point of the compounds and the results were compared with each other. the previous work and the experimental values.

\section{Data and Methodology}

Data set and theoretical descriptors. Melting points were taken from the recently published paper. ${ }^{\text {ti }}$ The data are mostly for the compounds that are solid at roon temperature but also include some liquids and gaseous compounds. The melting points are spread between -118 and $345^{\circ} \mathrm{C}$. The zmatrices (molecular models) were constructed with HyperChem 7.0 and molecular structures were optimized using AMl algorithm. ${ }^{+4}$ In order to calculate the theoretical descriptors, Dragon package version 2.1 was used. ${ }^{+5}$ For this propose the output of the HyperChem software for each compound fed into the Dragon program and the descriptors were calculated. As a result. a total of 1481 theoretical descriptors were calculated for each compound in data sets (323 compounds).

Data pretreatment. The theoretical descriptors were reduced by the following procedure: 1) descriptors that are constant have been eliminated ( 292 descriptors). 2 ) in addition, to decrease the redundancy existing in the descriptors data matrix, the correlation of descriptors with each other and with melting point of the molecules are examined. and collinear descriptors $(R>0.9)$ are detected. Those of the descriptors which have the pair wise correlation coefficient above 0.9 and having the lower correlation with melting point values are removed from the data matrix ( 758 descriptors). 3) before statistical analysis, the descriptors are scaled to zero mean and unit variance (autoscaling procedure). The data matrix (431 descriptors) is subjected to principal component analysis using Matlab software package. ${ }^{16}$ Multiparameter linear regression was obtained using spss software. ${ }^{+7}$

Genetic algorithm (GA). To select the most relevant principal components, evolution of population was simulated ${ }^{18.52}$ Each individual of the population defined by a chromosome of binary values represented a subset of principal components. The number of genes at each clromosome was equal to the number of principal components. The population of the first generation was selected randomly. A gene took a value of $\mathrm{I}$ if its corresponding principal component was included in the subset: otherwise, it took a value of zero. The number of genes with a value of 1 was kept relatively low to have a small subset of principal components. ${ }^{52}$ that is, the probability of generating 0 for a gene was set greater (at least $60 \%$ ) than the value of 1 . The operators used here were crossover and mutation. The probability of the application of these operators was varied linearly with generation renewal $(0-0.1 \%$ for mutation and $60-90 \%$ for crossover). The population size was varied between 50 and 250 for different GA runs. For a typical run. the evolution of the generation was stopped when $90 \%$ of the generations took the same fitness. The GA program was written in Matlab $6.5^{53}$

Artificial neural network (ANN). A feed forward artificial neural network with a back-propagation of error algorithm was used to process the non-linear relationship between the selected principal components and the melting point. The number of input nodes in the ANN was equal to the number of PC's. The ANN models confined to a single hidden layer because the network with more than one hidden layer would be harder to train. A three-layer network with a sigmoid transfer function was designed. The initial weights were randomly selected between 0 and 1. Optimization of the weights and biases was carried out according to the resilient back-propagation algorithm. The data set was randomly divided into three groups: a training set. a validation set and a prediction set consisting of 195,64 and 64 molecules. respectively. The training and validation sets were used for the model generation and the prediction set was used for evaluation of the generated model. The performances of training. validation and prediction of models are 
evaluated by the mean percentage deviation (MPD) and root mean square error (RMSE), which are defuned as follows:

$$
\begin{aligned}
& \mathrm{MPD}=\frac{100}{N} \sum_{s=1}^{N}\left|\frac{P_{i}^{\mathrm{eXp}}-P_{i}^{c a t}}{P_{i}^{\mathrm{exp}}}\right| \\
& \text { RMSE }=\sqrt{\sum_{i=1}^{N} \frac{\left(P_{1}^{\mathrm{exp}}-P_{i}^{c a l}\right)^{2}}{N}}
\end{aligned}
$$

where $P_{3}^{\text {exp }}$ and $P_{3}^{c a l}$ are experimental and calculated values of melting point with the models and $N$ denote the number of data points. Individual percent deviation (IPD) is defuned as follows:

$$
\mathrm{IPD}=100 \times\left(\frac{P_{i}^{c a l}-P_{i}^{\mathrm{exp}}}{P_{i}^{\exp }}\right)
$$

The processing of the data was carried using Matlab $6.5^{+6}$ The neural networks were implemented using Neural Network Toolbox Ver. 4.0 for Matlab. ${ }^{54}$

\section{Results and Discussion}

Principal component analysis. After the elimination of the constant and one of the collinear ones. 431 descriptors remained from 1481 theoretical descriptors calculated for the compounds. The results of application of PCA on the descriptors data matrix were shown that $99.9 \%$ of the variances in the descriptors data matrix are explained by 234 first PC's. Therefore. we focused our analysis on these PC's. and the reminders, which are noisy factors. were not considered.

Principal component-genetic algorithm-multiparameter linear regression. Obtaining the number of significant principal components is the main problem in the PCA-based methods. The first 234 principal components ( $\mathrm{PC}$ 's) were found to explain more than $99.9 \%$ of variances in the original data matrix. As noted previously not all of the PC's is informative for QSAR/QSPR modeling. ${ }^{5.27}$ Then, we used GA for the selection of the most relevant PC's instead of the older methods. The selected PC's are PC1. PC2. PC3. PC4, PC5, PC6, PC7, PC9, PC15, PC32, PC33, PC36. $\mathrm{PC} 37 . \mathrm{PC} 39$ and $\mathrm{PC} 86$. As can be seen the selected principal components are not based on their eigenvalue. For example. PC9 and PC15 are selected and PC8 is not considered in the model. This is due to the fact the information contents of some extracted PC's may not be in the same direction of the activity data. Multiparameter linear correlation of melting point values for 195 compounds in training set was obtained using the fifteen principal components. The calculated values of melting point for the compounds in training. validation and prediction sets using the PC-GA-MLR model have been plotted versits the experimental values of it (Figure 1).

Principal component-genetic algorithm-artificial neural network. To process the non-linear relationships exists bet-

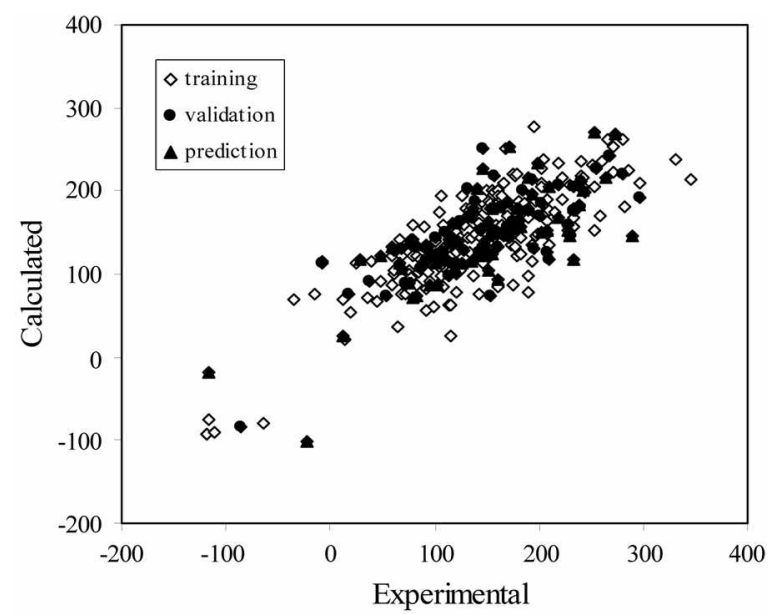

Figure 1. Plot of calculated values of the melting point using the PC-GA-MLR model versus the experimental values of it for training, validation and prediction sets.

ween the melting point and the PC's. the ANN modeling method combined with PCA for dimension reduction and GA for feature selection was enployed. A principal component-genetic algorithm-artificial neural network (PC-GAANN) model. which combines the PC's with ANN, is another PC-based calibration teclunique for non-linear modeling between the PC's and dependent variables. ${ }^{25.28}$ The input vectors were the set of PC's, which were selected by GA. and therefore. the number of nodes in the input layer was dependent on the number of selected PC's. In the PC-GAMLR model it is assumed that the PC's are independent of each other and truly additive relevant to the property under study. ANNs are particularly well-suited for QSAR/QSPR models because of their ability to extract non-linear information present in the data matrix. For this reason the next step in this work was generation of the ANN model. There are no rigorous theoretical principles for choosing the proper network topology: so different structures were tested in order to obtain the optimal hidden neurons and training cycles. ${ }^{3-4-42}$ Before training the network. the number of nodes in the hidden layer was optimized. In order to optimize the number of nodes in the hidden laver. several training sessions were conducted with different numbers of hidden nodes (from one to thirty two). The root mean square error of training (RMSET) and validation (RMSEV) sets were obtained at various iterations for different number of neurons at the hidden layer and the minimum value of RMSEV was recorded as the optimum value. Plot of RMSET and RMSEV versis the number of nodes in the hidden layer has been shown in Figure 2. It is clear that the twenty nine nodes in hidden laỵer is the optimum value.

This network consists of fifteen inputs (including PC1. PC2, PC3, PC4, PC5, PC6, PC7, PC9. PC15, PC32, PC33. PC36. PC37. PC39 and PC86), the same PC's in the PC-GAMLR model. and one output for melting point. Then an ANN with architecture 15-29-1 was generated. It is noteworthy that training of the network was stopped when the RMSEV started to increases i.e. when overtraining begins. 


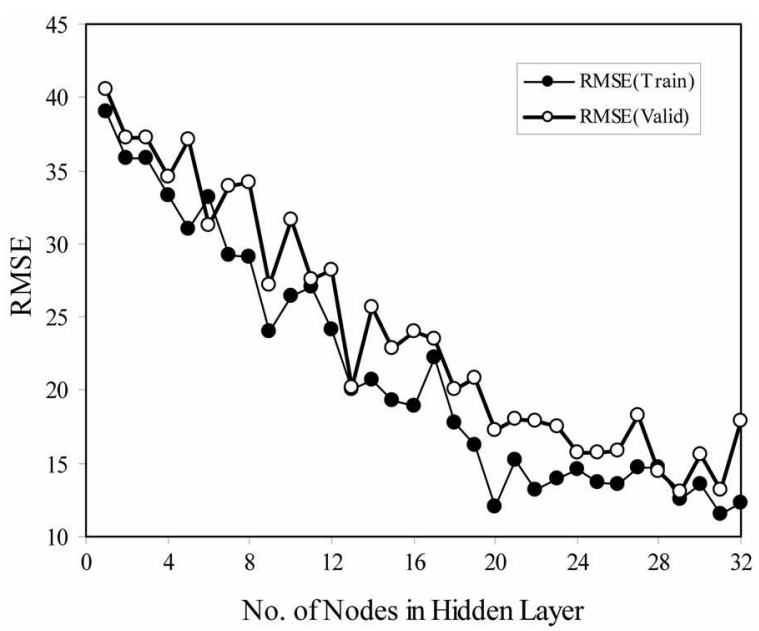

Figure 2. Plot of RMSE for training and validation sets versts the number of nodes in hidden laver.

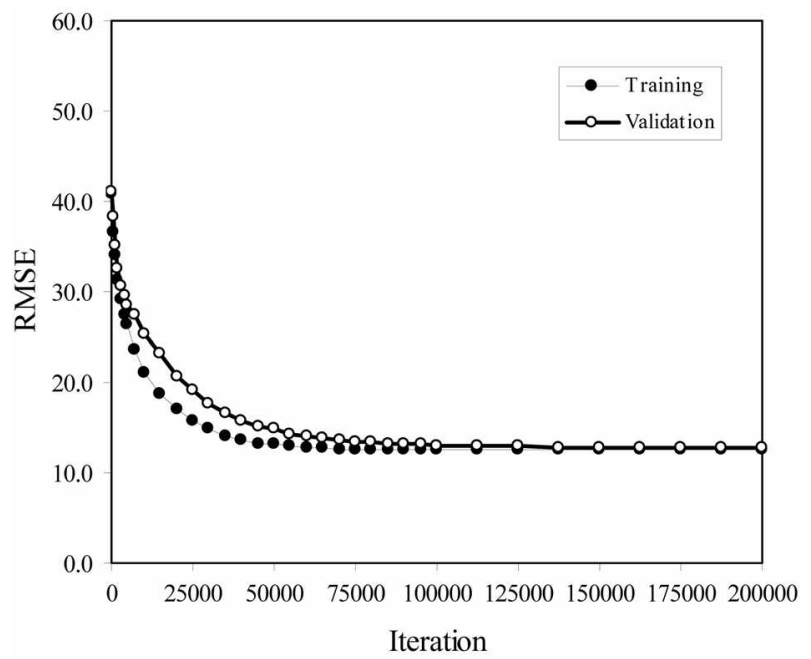

Figure 3. Plot of RMSE for training and validation sets rersus the number of iterations.

The overtraining causes the ANN to loose its prediction power. ${ }^{31}$ Therefore. during training of the network, it is desirable that iterations are stopped when overtraining begins. To control the overtraining of the network during the training procedure the values of RMSET and RMSEV were calculated and recorded to monitor the extent of the learning in various iterations. Results showed that overfitting did not see in the optimum architecture (Figure 3 ).

The generated ANN was then trained using the training and validation sets for the optimization of the weights and biases. For the evaluation of the predictive power of the generated ANN. an optimized network was applied for prediction of the melting point values in the prediction set. which were not used in the modeling procedure (Table 1). The calculated values of melting point for the compounds in training. validation and prediction sets using the ANN model have been plotted versis the experimental values of it in Figure 4 .

It is clear that the calculated values of melting point are in good agreement with those of the experimental values. The

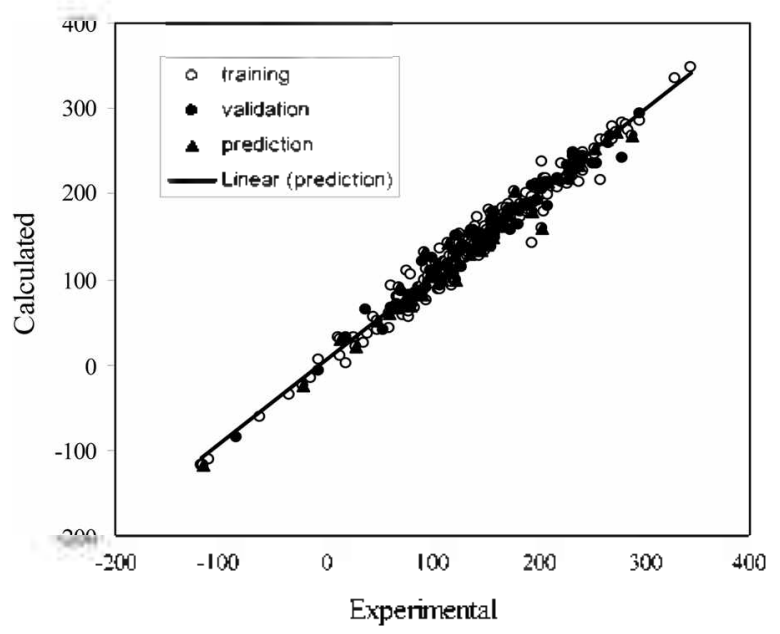

Figure 4. Plot of calculated values of the melting point using the PC-GA-ANN model versis the experimental values of it for training, validation and prediction sets.

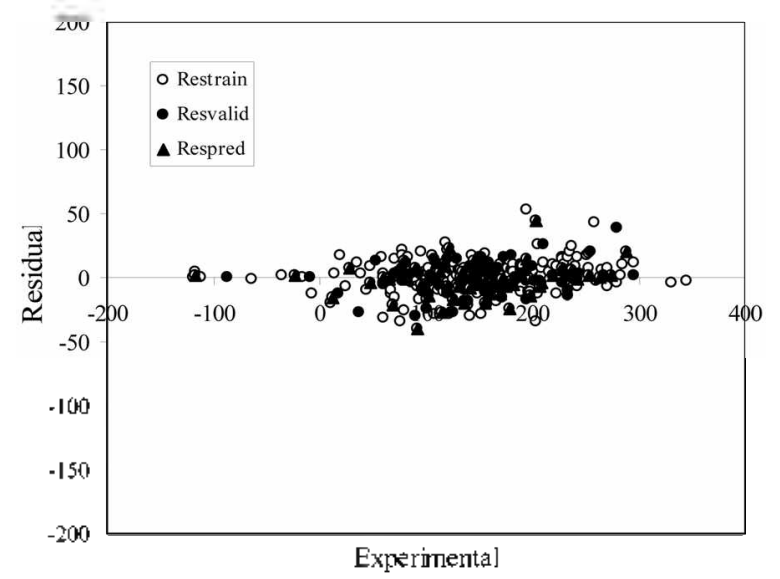

Figure 5. Plot of the residual for calculated values of the melting point using the PC-GA-ANN model versus the experimental values of it.

correlation equation for all of the calculated values of melting point (Mp) from the ANN model and the experimental values is as follows:

$$
\mathrm{Mp}(\mathrm{cal})=0.969 \mathrm{Mp}(\exp )+4.381
$$

$(\mathrm{R}=0.9850: \mathrm{MPD}=9.326: \mathrm{RMSE}=12.623: \mathrm{F}=10445.99)$

Similarly. correlation of $\mathrm{Mp}$ (cal) versus $\mathrm{Mp}(\mathrm{exp})$ values in the prediction set gives equation (5):

$$
\begin{gathered}
\mathrm{Mp}(\mathrm{cal})=0.972 \mathrm{Mp}(\exp )+5.623 \\
(\mathrm{R}=0.9843 ; \mathrm{MPD}=9.119 ; \mathrm{RMSE}=12.767 ; \mathrm{F}=1930.99
\end{gathered}
$$

Plot of the residual for melting point values in the training. validation and prediction sets versus the experimental values of it has been illustrated in Figure 5. It is clear that the propagation of errors in both sides of zero is random. Then there is not systematic error in the model.

As a result. it was found that properly selected and trained neural network could fairly represent dependence of melting point for the drug-like compounds on the PC's. Then the 
Table 1. Experimental and calculated values of melting point for the drug-like compounds in training, validation and prediction sets using PC-GA-MLR and PC-GA-ANN models along with the residual for the calculated values by PC-GA-ANN model

\begin{tabular}{|c|c|c|c|c|}
\hline No. & Compound & Experimental & $\begin{array}{c}\text { Cal } \\
(\mathrm{PC}-\mathrm{GA}-\mathrm{ANN})\end{array}$ & Res. \\
\hline & Training & & & \\
\hline 1 & Halothane & -118 & -118.3 & 0.3 \\
\hline 2 & Diethyl ether & -116.3 & -120.2 & 3.9 \\
\hline 3 & Ethylene oxide & -111.3 & -112.0 & 0.7 \\
\hline 4 & Chloroforn & -63.7 & -62.3 & -1.4 \\
\hline 5 & Methosyflurane & -35 & -35.9 & 0.9 \\
\hline 6 & Benzyl alcohol & -15.3 & -14.9 & -0.4 \\
\hline 7 & Nicotinyl alcolnol & -7.7 & 5.1 & -12.8 \\
\hline 8 & Amplietamine & 11.3 & 31.8 & -20.5 \\
\hline 9 & Glyceryl trinitrate & 13.5 & 10.5 & 30 \\
\hline 10 & Propofol & 19 & 2.2 & 16.8 \\
\hline 11 & Nikethamide & 25 & 32.1 & -7.1 \\
\hline 12 & Ephedrine & 36 & 24.7 & 11.3 \\
\hline 13 & Methyl nicotinate & 39 & 36.7 & 2.3 \\
\hline 14 & Trimipramine & 45 & 55.0 & -100 \\
\hline 15 & Phencarbanide & 48 & 39.7 & 8.3 \\
\hline 16 & Hyoscine & 59 & 43.4 & 15.6 \\
\hline 17 & Ptometazine & 60 & 57.5 & 2.5 \\
\hline 18 & Gemfibrozil & 61 & 92.0 & -310 \\
\hline 19 & Procaine & 61 & 65.5 & -4.5 \\
\hline 20 & Dichloralphenazone & 65.5 & 67.1 & -1.6 \\
\hline 21 & Etomidate & 67 & 80.3 & -13.3 \\
\hline 22 & Lignocaine & 67.5 & 79.9 & -12.4 \\
\hline 23 & Penbutolol & 68 & 78.5 & -10.5 \\
\hline 24 & Betaxolol & 71 & 86.4 & -15.4 \\
\hline 25 & Mephentesin & 71.5 & 57.3 & 14.2 \\
\hline 26 & Phenadosone & 75 & 71.1 & 3.9 \\
\hline 27 & Ibuprofen & 76 & 110.7 & -34.7 \\
\hline 28 & Mebutannate & 77 & 71.4 & 5.6 \\
\hline 29 & Oxprenolol & 77.5 & 56.5 & 210 \\
\hline 30 & Methadone & 78 & 61.1 & 16.9 \\
\hline 31 & Allylestrenol & 80 & 800 & 00 \\
\hline 32 & Banifylline & 80 & 106.1 & -26.1 \\
\hline 33 & Nabumetone & 80 & 67.0 & 130 \\
\hline 34 & Anileridine & 83 & 83.3 & -0.3 \\
\hline 35 & Fentanyl & 83 & 67.2 & 15.8 \\
\hline 36 & Amplietaninil & 85 & 84.2 & 0.8 \\
\hline 37 & Methdilazine & 87 & 91.1 & -4.1 \\
\hline 38 & Noxythiolin & 88 & 90.1 & -2.1 \\
\hline 39 & Vunylbital & 90 & 83.4 & 6.6 \\
\hline 40 & Phenindamine & 91 & 92.9 & -1.9 \\
\hline 41 & Carisoprodol & 92 & 87.6 & 4.4 \\
\hline 42 & Beclamide & 92.5 & 99.1 & -6.6 \\
\hline 43 & Penphenazine & 94 & 110.8 & -16.8 \\
\hline 44 & Thenalidine & 95 & 75.2 & 19.8 \\
\hline 45 & Tropicamide & 96.5 & 96.6 & -0.1 \\
\hline 46 & Aldicarb & 99 & 97.6 & 1.4 \\
\hline 47 & Acetylpheneturide & 100 & 96.2 & 3.8 \\
\hline 48 & Phenocoll & 100.5 & 117.7 & -17.2 \\
\hline 49 & Piperidione & 102 & 106.1 & -4.1 \\
\hline 50 & Isoxsuprine & 102.5 & 94.8 & 7.7 \\
\hline
\end{tabular}

Table 1. Continued

\begin{tabular}{|c|c|c|c|c|}
\hline No. & Compound & Experimental & $\begin{array}{c}\text { Cal } \\
(\mathrm{PC}-\mathrm{GA}-\mathrm{ANN})\end{array}$ & Res. \\
\hline 51 & Meprobamate & 104 & 104.1 & -0.1 \\
\hline 52 & Gentamicin & 105 & 104.9 & 0.1 \\
\hline 53 & Physotigmine & 105.5 & 88.2 & 17.3 \\
\hline 54 & Bupivacaine & 107 & 89.2 & 17.8 \\
\hline 55 & Amidopyrine & 108 & 136.4 & -28.4 \\
\hline 56 & Acecarbromal & 109 & 105.4 & 3.6 \\
\hline 57 & Celiprolol & 110 & 107.8 & 2.2 \\
\hline 58 & Tolnattate & 111 & 121.1 & -10.1 \\
\hline 59 & Amphotalide & 113 & 119.7 & -6.7 \\
\hline 60 & Valnoctamide & 113.5 & 111.1 & 2.4 \\
\hline 61 & Ifenprodil & 114 & 115.5 & -1.5 \\
\hline 62 & Bamipine & 115 & 104.8 & 10.2 \\
\hline 63 & Alverine & 116 & 128.1 & -12.1 \\
\hline 64 & Pericyazine & 116 & 116.1 & -0.1 \\
\hline 65 & Atropine & 118 & 114.8 & 3.2 \\
\hline 66 & Morphazinamide & 118.5 & 91.8 & 26.7 \\
\hline 67 & Chlophedianol & 120 & 125.4 & -5.4 \\
\hline 68 & Pridinol & 120 & 99.3 & 20.7 \\
\hline 69 & Terbutaline & 120.5 & 1308 & -10.3 \\
\hline 70 & Capobenic acid & 121 & 124.6 & -3.6 \\
\hline 71 & Propizepine & 122 & 1500 & -28.0 \\
\hline 72 & Nadolol & 124 & 117.9 & 6.1 \\
\hline 73 & Bamethan & 125 & 114.0 & 11.0 \\
\hline 74 & Nimodipine & 125 & 126.3 & -1.3 \\
\hline 75 & Mecloqualone & 126 & 153.3 & -27.3 \\
\hline 76 & Febantel & 129 & 128.3 & 0.7 \\
\hline 77 & Clonidine & 130 & 136.1 & -6.1 \\
\hline 78 & $\mathrm{Xy}$ lometazoline & 131 & 124.8 & 6.2 \\
\hline 79 & Diazepam & 133 & 127.3 & 5.7 \\
\hline 80 & Thozalinone & 133 & 133.5 & -0.5 \\
\hline 81 & Aminorex & 136 & 145.7 & -9.7 \\
\hline 82 & Praziquantel & 136 & 128.2 & 7.8 \\
\hline 83 & Simvastatin & 136.5 & 142.4 & -5.9 \\
\hline 84 & Butalbital & 138 & 138.8 & -0.8 \\
\hline 85 & Phenazopy ridine & 139 & 147.9 & -8.9 \\
\hline 86 & Erythrocentauluin & 140 & 161.0 & -21.0 \\
\hline 87 & Carbaryl & 142 & 144.1 & -2.1 \\
\hline 88 & Fexofenadine & 142 & 141.0 & 1.0 \\
\hline 89 & Letosteine & 142 & 149.8 & -7.8 \\
\hline 90 & Acetylsalicylic acid & 142.4 & 172.9 & -30.5 \\
\hline 91 & Tetrazepam & 144 & 126.4 & 17.6 \\
\hline 92 & Felodipin & 145 & 140.9 & 4.1 \\
\hline 93 & Metoclopramide & 146.5 & 153.7 & -7.2 \\
\hline 94 & Atenolol & 147 & 152.7 & -5.7 \\
\hline 95 & clotrimazole & 147 & 144.6 & 2.4 \\
\hline 96 & Salacetamide & 148 & 157.1 & -9.1 \\
\hline 97 & Morazone & 149 & 146.7 & 2.3 \\
\hline 98 & Astemizole & 149.1 & 162.3 & -13.2 \\
\hline 99 & Acemetacin & 150 & 134.2 & 15.8 \\
\hline 100 & Mafenide & 151 & 1409 & 10.1 \\
\hline 101 & Haloperidol & 151.5 & 148.2 & 3.3 \\
\hline 102 & Glymidine & 152 & 152.4 & -0.4 \\
\hline 103 & Azatadine & 153 & 148.1 & 4.9 \\
\hline 104 & Testosterone & 153 & 180.9 & -27.9 \\
\hline
\end{tabular}


Table 1. Continued

\begin{tabular}{|c|c|c|c|c|}
\hline No. & Compound & Experimental & $\begin{array}{c}\text { Cal } \\
(\mathrm{PC}-\mathrm{GA}-\mathrm{ANN})\end{array}$ & Res. \\
\hline 105 & Taurolidine & 154 & 152.8 & 1.2 \\
\hline 106 & Colchicane & 156 & 160.7 & -4.7 \\
\hline 107 & moricizine & 156 & 157.3 & -1.3 \\
\hline 108 & Oneprazole & 156 & 150.3 & 5.7 \\
\hline 109 & Urapidil & 156 & 137.3 & 18.7 \\
\hline 110 & Salicylic acid & 157 & 163.0 & -60 \\
\hline 111 & Succisulfone & 157 & 152.0 & 50 \\
\hline 112 & Lidoflazine & 159 & 153.8 & 5.2 \\
\hline 113 & Azacyclonol & 160 & 158.1 & 1.9 \\
\hline 114 & Benzydanine & 160 & 164.0 & -40 \\
\hline 115 & Didanosine & 160 & 156.1 & 3.9 \\
\hline 116 & Ketorolac & 160.5 & 178.2 & -17.7 \\
\hline 117 & Oxaprozin & 160.5 & 161.7 & -1.2 \\
\hline 118 & Aldosterone & 164 & 176.3 & -12.3 \\
\hline 119 & Pizotifenn & 164 & 169.8 & -5.8 \\
\hline 120 & Tolrestat & 164 & 175.0 & -110 \\
\hline 121 & Lorazepann & 166 & 184.1 & -18.1 \\
\hline 122 & Sulfamethoxazole & 167 & 161.7 & 5.3 \\
\hline $12 \hat{3}$ & Chlortetracycline & 168.5 & 168.3 & 0.2 \\
\hline 124 & Glyburide & 169 & 170.0 & -1.0 \\
\hline 125 & Benperidol & 170 & 161.2 & 8.8 \\
\hline 126 & Metopinazine & 170 & 160.5 & 9.5 \\
\hline 127 & Tolazamide & 170 & 183.7 & -13.7 \\
\hline 128 & Isoniazid & 172 & 188.2 & -16.2 \\
\hline 129 & Hydralazine & 172.5 & 166.3 & 6.2 \\
\hline 130 & Nifedipine & 173 & 179.0 & -60 \\
\hline $1 \hat{3} 1$ & Lovastatin & 174.5 & 159.5 & 150 \\
\hline 132 & Amisonetradine & 175 & 167.6 & 7.4 \\
\hline $13 \hat{3}$ & Acifran & 176 & 179.3 & -3.3 \\
\hline 134 & Melphalan & 177 & 170.2 & 68 \\
\hline 135 & Propallỵlonal & 177 & 179.7 & -2.7 \\
\hline 136 & Sulpiride & 178 & 184.0 & -60 \\
\hline 137 & Zomepirac & 178 & 177.0 & 1.0 \\
\hline 138 & Nomifensine & 179 & 165.8 & 13.2 \\
\hline 139 & Sulthianne & 180 & 174.8 & 5.2 \\
\hline 140 & Acepromazine & 182.5 & 174.7 & 7.8 \\
\hline 141 & Amplnenidone & 182.5 & 173.2 & 9.3 \\
\hline 142 & Sulfacetamide & 183 & 179.4 & 3.6 \\
\hline $14 \hat{3}$ & Bezafibrate & 186 & 186.8 & -0.8 \\
\hline 144 & Acetoheramide & 189 & 179.6 & 9.4 \\
\hline 145 & Pyrazinamide & 189 & 200.8 & -11.8 \\
\hline 146 & Clomipramine & 189.5 & 184.5 & 50 \\
\hline 147 & Carbamazepine & 190 & 181.0 & 9.0 \\
\hline 148 & Ennbutrannide & 190.5 & 181.4 & 9.1 \\
\hline 149 & Apronal & 194 & 197.3 & -3.3 \\
\hline 150 & Clebopride & 194 & 141.2 & 52.8 \\
\hline 151 & Methotrexate & 195 & 196.4 & -1.4 \\
\hline 152 & Aceglutamide & 197 & 189.8 & 7.2 \\
\hline $15 \hat{3}$ & Aceneocoumarol & 197 & 208.6 & -11.6 \\
\hline 154 & Furonazide & 199 & 209.9 & -10.9 \\
\hline 155 & Polythiazide & 202.5 & 205.2 & -2.7 \\
\hline 156 & Ampicillin & 203 & 237.0 & -34.0 \\
\hline 157 & Picrotoxin & 203 & 199.1 & 3.9 \\
\hline
\end{tabular}

Table 1. Continued

\begin{tabular}{|c|c|c|c|c|}
\hline No. & Compound & Experimental & $\begin{array}{c}\text { Cal } \\
\text { (PC-GA-ANN) }\end{array}$ & Res. \\
\hline 158 & Glipizide & 205 & 218.5 & -13.5 \\
\hline 159 & Oxazepam & 205.5 & 179.5 & 26.0 \\
\hline 160 & Lonidamine & 207 & 206.8 & 0.2 \\
\hline 161 & Amodiaquine & 208 & 206.3 & 1.7 \\
\hline 162 & Indoramin & 208 & 217.2 & -9.2 \\
\hline 163 & Vigabatrin & 209 & 201.8 & 7.2 \\
\hline 164 & Methetion & 210 & 198.8 & 11.2 \\
\hline 165 & Pimozide & 216 & 211.9 & 4.1 \\
\hline 166 & Oxycodone & 219 & 208.3 & 10.7 \\
\hline 167 & Hydroxyprogesterone & 222.5 & 213.5 & 9.0 \\
\hline 168 & Hydrocortisone & 223 & 235.9 & -12.9 \\
\hline 169 & Apazone & 228 & 212.5 & 15.5 \\
\hline 170 & Acitretin & 229 & 215.0 & 140 \\
\hline 171 & Nalidisic acid & 229.5 & 219.1 & 10.4 \\
\hline 172 & Salinazid & 232.5 & 235.6 & -3.1 \\
\hline 173 & Diaveridine & 233 & 227.8 & 5.2 \\
\hline 174 & Phenopyrazone & 233 & 217.5 & 15.5 \\
\hline 175 & Pyrimethamine & 233.5 & 230.3 & 3.2 \\
\hline 176 & Nicotinic acid & 235.5 & 215.7 & 19.8 \\
\hline 177 & Caftiene & 238 & 213.3 & 24.7 \\
\hline 178 & Prednisolone & 240.5 & 231.7 & 8.8 \\
\hline 179 & Cromolyn & 241 & 238.6 & 2.4 \\
\hline 180 & Clometacin & 242 & 225.9 & 16.1 \\
\hline 181 & Domperidone & 242.5 & 249.3 & -6.8 \\
\hline 182 & Metolazone & 252 & 235.4 & 16.6 \\
\hline 183 & Finasteride & 253 & 245.9 & 7.1 \\
\hline 184 & Nifenazone & 253 & 234.4 & 18.6 \\
\hline 185 & Pemoline & 259 & 215.5 & 43.5 \\
\hline 186 & Dexamethasone & 260 & 262.7 & -2.7 \\
\hline 187 & Ciprofloxacin & 266 & 259.9 & 6.1 \\
\hline 188 & Hydrotlumethiazide & 270.5 & 262.8 & 7.7 \\
\hline 189 & Acefylline & 271 & 278.1 & -7.1 \\
\hline 190 & Dantrolene & 279.5 & 283.8 & -4.3 \\
\hline 191 & Fluorouracil & 283 & 281.2 & 1.8 \\
\hline 192 & Prazosin & 285 & 274.5 & 10.5 \\
\hline 193 & Enosolone & 296 & 284.7 & 11.3 \\
\hline 194 & Diazoxide & 330.5 & 334.5 & -40 \\
\hline 195 & $\begin{array}{l}\text { Orotic acid } \\
\text { Validation }\end{array}$ & 345 & 347.6 & -2.6 \\
\hline 196 & Trichlorethylene & -86 & -85.7 & -0.3 \\
\hline 197 & Methyl salicylate & -8 & -7.5 & -0.5 \\
\hline 198 & Benzyl benzoate & 18 & 31.4 & -13.4 \\
\hline 199 & Prilocaine & 37 & 63.9 & -26.9 \\
\hline 200 & Ethopropazine & 53 & 39.9 & 13.1 \\
\hline 201 & Isosorbide & 61 & 66.4 & -5.4 \\
\hline 202 & Fluanisone & 67.5 & 70.6 & -3.1 \\
\hline 203 & Disulfiram & 71 & 67.8 & 3.2 \\
\hline 204 & Ethylesterol & 77 & 69.4 & 7.6 \\
\hline 205 & Mosaverine & 78 & 81.0 & -3.0 \\
\hline 206 & Pentifylline & 82 & 708 & 11.2 \\
\hline 207 & Piprozolin & 86 & 83.4 & 2.6 \\
\hline 208 & Alclofenac & 91 & 1205 & -29.5 \\
\hline 209 & Ketoprofen & 94 & 904 & 3.6 \\
\hline
\end{tabular}


Table 1. Continued

\begin{tabular}{|c|c|c|c|c|}
\hline No. & Compound & Experimental & $\begin{array}{c}\text { Cal } \\
\text { (PC-GA-ANN) }\end{array}$ & Res. \\
\hline 210 & Cocaine & 98 & 109.3 & -11.3 \\
\hline 211 & Hycanthone & 100.6 & 124.4 & -23.8 \\
\hline 212 & Benzoyl peroside & 105 & 103.7 & 1.3 \\
\hline 213 & Metaraminol & 107.5 & 92.5 & 15.0 \\
\hline 214 & Flurbiprofen & 110 & 99.1 & 109 \\
\hline 215 & Acetanilide & 114 & 119.3 & -5.3 \\
\hline 216 & Dibenzepin & 116 & 109.3 & 6.7 \\
\hline 217 & Antazoline & 120 & 105.2 & 14.8 \\
\hline 218 & Acebutolol & 121 & 134.4 & -13.4 \\
\hline 219 & Benzarone & 124.3 & 1509 & -26.6 \\
\hline 220 & Tolbutamide & 128.5 & 113.8 & 14.7 \\
\hline 221 & Benzylmorphine & 132 & 135.8 & -3.8 \\
\hline 222 & Mephenytoin & 136 & 154.0 & -180 \\
\hline 223 & Alizapride & 139 & 157.2 & -18.2 \\
\hline 224 & Cimetidine & 142 & 133.5 & 8.5 \\
\hline 225 & Carbutannide & 144 & 145.6 & -1.6 \\
\hline 226 & Pyrinoline & 146.5 & 153.9 & -7.4 \\
\hline 227 & Thialbarbital & 148 & 148.2 & -0.2 \\
\hline 228 & Salbutannol & 151 & 143.7 & 7.3 \\
\hline 229 & Bufexamac & 153 & 138.0 & 150 \\
\hline 230 & Ketobemidone & 156 & 167.4 & -11.4 \\
\hline $2 \hat{3} 1$ & Dihydromopline & 157 & 178.3 & -21.3 \\
\hline 232 & Metronidazole & 159 & 148.2 & 10.8 \\
\hline 233 & Methallatal & 160 & 158.4 & 1.6 \\
\hline 234 & Halazepann & 164 & 1609 & 3.1 \\
\hline 2.35 & Clobazan & 167 & 159.3 & 7.7 \\
\hline 236 & Sumatriptan & 169 & 161.2 & 7.8 \\
\hline 237 & Hydroquinine & 172 & 181.5 & -9.5 \\
\hline 238 & Heptabarbital & 174 & 158.1 & 15.9 \\
\hline 239 & Mephobarbital & 176 & 181.6 & -5.6 \\
\hline 240 & Ximoprofèn & 178 & 183.7 & -5.7 \\
\hline 241 & Androstanolone & 181 & 164.1 & 169 \\
\hline 242 & Zox azolamine & 184 & 183.8 & 0.2 \\
\hline $24 \hat{3}$ & Verazide & 189 & 186.0 & 30 \\
\hline 244 & Acediasulfone & 194 & 210.4 & -16.4 \\
\hline 245 & Probenecid & 195 & 190.4 & 4.6 \\
\hline 246 & Alphadolone & 200 & 192.0 & 8.0 \\
\hline 247 & Ursodiol & 203 & 205.5 & -2.5 \\
\hline 248 & Sotalol & 207 & 209.4 & -2.4 \\
\hline 249 & Acecainide & 210 & 184.6 & 25.4 \\
\hline 250 & Propylthiouracil & 219 & 218.1 & 0.9 \\
\hline 251 & Azapropazone & 228 & 232.9 & -4.9 \\
\hline 252 & Chlorazanil & 233 & 247.6 & -14.6 \\
\hline 253 & Sulfamerazine & 234 & 243.9 & -9.9 \\
\hline 254 & Amiloride & 241 & 244.4 & -3.4 \\
\hline 255 & Azathioprine & 243.5 & 240.3 & 3.2 \\
\hline 256 & Morphine & 255 & 234.7 & 20.3 \\
\hline 257 & Fostosal & 268 & 266.9 & 1.1 \\
\hline 258 & Moxestrol & 280 & 241.8 & 38.2 \\
\hline \multirow[t]{2}{*}{259} & Flucytosine & 296 & 294.2 & 1.8 \\
\hline & Prediction & & & \\
\hline 260 & Sevoflurane & -116 & -116.7 & 0.7 \\
\hline 261 & Tetrachloroethylene & -22.3 & -24.1 & 1.8 \\
\hline 262 & Paraldeliyde & 12.6 & 28.9 & -16.3 \\
\hline 263 & Tranylcypromine & 28 & 21.0 & 7.0 \\
\hline 264 & Ifostamide & 48 & 51.7 & -3.7 \\
\hline 265 & Triprolidine & 60 & 59.3 & 0.7 \\
\hline
\end{tabular}

Table 1. Continued

\begin{tabular}{|c|c|c|c|c|}
\hline No. & Compound & Experimental & $\begin{array}{c}\text { Cal } \\
\text { (PC-GA-ANN) }\end{array}$ & Res. \\
\hline 266 & Chlorambucil & 66 & 67.2 & -1.2 \\
\hline 267 & Ranitidine & 69 & 90.9 & -21.9 \\
\hline 268 & Propoxyphene & 75 & 70.3 & 4.7 \\
\hline 269 & Etisazol & 78 & 74.1 & 3.9 \\
\hline 270 & Guaiphenesirl & 80 & 67.5 & 12.5 \\
\hline 271 & Metrifonate & 83 & 84.0 & -1.0 \\
\hline 272 & Benzocaine & 90 & 82.6 & 7.4 \\
\hline 273 & Maprotiline & 92 & 132.4 & -40.4 \\
\hline 274 & Tamoxifen & 96 & 102.2 & -6.2 \\
\hline 275 & Metaproterenol & 100 & 106.0 & -60 \\
\hline 276 & Difenidol & 103.5 & 118.1 & -14.6 \\
\hline 277 & Pipobroman & 106 & 107.3 & -1.3 \\
\hline 278 & Acetyloysteine & 109.5 & 98.4 & 11.1 \\
\hline 279 & Cyproheptad ine & 113 & 108.4 & 4.6 \\
\hline 280 & Flupirtine & 115 & 142.8 & -27.8 \\
\hline 281 & Moperone & 118 & 110.0 & 8.0 \\
\hline 282 & Temazepam & 120 & 127.7 & -7.7 \\
\hline 283 & Benzoic acid & 122.4 & 99.0 & 23.4 \\
\hline 284 & Lofexidine & 126 & 142.9 & -16.9 \\
\hline 285 & Bitoscanate & 131 & 138.2 & -7.2 \\
\hline 286 & Phenacetin & 134.5 & 130.0 & 4.5 \\
\hline 287 & Sulfinpyrazone & 136.5 & 1569 & -20.4 \\
\hline 288 & Aprobarbitone & 141 & 141.2 & -0.2 \\
\hline 289 & Proglumide & $1+2$ & 149.9 & -7.9 \\
\hline 290 & Ketoconazole & 146 & 133.5 & 12.5 \\
\hline 291 & Cloricromen & 147.5 & 139.3 & 8.2 \\
\hline 292 & Felbamate & 151 & 140.0 & 11.0 \\
\hline 293 & Naproxen & 152 & 157.5 & -5.5 \\
\hline 294 & Amobarbital & 156 & 176.3 & -20.3 \\
\hline 295 & Phenallymal & 156 & 158.4 & -2.4 \\
\hline 296 & Warfarin & 157 & 148.4 & 8.6 \\
\hline 297 & Bucetirl & 160 & 172.4 & -12.4 \\
\hline 298 & Famotidine & 163 & 166.9 & -3.9 \\
\hline 299 & Tyramine & 164 & 169.3 & -5.3 \\
\hline 300 & Acetaminophen & 169 & 176.5 & -7.5 \\
\hline 301 & Risperdone & 170 & 183.1 & -13.1 \\
\hline 302 & Tetracycline & 172.5 & 174.3 & -1.8 \\
\hline 303 & Amoxapine & 175.5 & 182.6 & -7.1 \\
\hline 304 & Oxymetholone & 178 & 202.9 & -24.9 \\
\hline 305 & Dextromoramide & 180 & 182.5 & -2.5 \\
\hline 306 & Clozapine & 183 & 188.3 & -5.3 \\
\hline 307 & Glisosepid & 189 & 187.6 & 1.4 \\
\hline 308 & Spiperone & 190 & 187.4 & 2.6 \\
\hline 309 & Hymecromone & 194 & 179.2 & 14.8 \\
\hline 310 & Piroxicam & 198 & 212.6 & -14.6 \\
\hline 311 & Carosazone & 203 & 158.5 & 4.5 \\
\hline 312 & Baclofen & 207 & 214.7 & -7.7 \\
\hline 313 & Buprenorphine & 209 & 213.5 & -4.5 \\
\hline 314 & Griseofulvin & 219 & 217.0 & 2.0 \\
\hline 315 & Thioacetazone & 227.5 & 220.7 & 68 \\
\hline 316 & Oxibendazole & 230 & 224.4 & 5.6 \\
\hline 317 & Ubenimex & 233 & 231.6 & 1.4 \\
\hline 318 & Lotrifen & 238 & 232.8 & 5.2 \\
\hline 319 & Zolimidine & 242 & 244.0 & -2.0 \\
\hline 320 & Flumequine & 253 & 252.0 & 1.0 \\
\hline 321 & Reserpine & 264.5 & 264.3 & 0.2 \\
\hline 322 & Hydrochlorthiazide & 274 & 272.4 & 1.6 \\
\hline 323 & Acedapsone & 289 & 268.8 & 20.2 \\
\hline
\end{tabular}


optinized neural network could sinulate the complicated nonlinear relationship between melting point values and the PC's. The RMSE of 48.176 for the prediction set by the PC. GA-MLR model should be compared with the value of 12.77 for the PC-GA-ANN model. As can be seen. ability of the proposed model to predict the melting point is very higher than the QSPR models proposed in recently published paper (RMSE of 12.767 should be compared with 40.7 ${ }^{\circ} \mathrm{C}$ ). It can be seen that although parameters appearing in the PC-GA-MLR model are used as inputs for the generated PC. GA-ANN model. the statistics has shown a large inprovement. These inprovements are due to the fact that melting point of the compounds shows non-linear correlations with the principal components.

The melting point of a compound is governed by the intermolecular hydrogen-bonding ability of the molecules. the molecular packing in crystals (effects from molecular shape, size. and symunetry), and other intermolecular interactions such as charge transfer and dipole-dipole interactions in the solid phase. The solubility of a compound can be regarded as a partitioning of the compound between its crystal lattice and the solvent. If the forces holding the molecule in the crystal are high, then the solubility will be low. For the same reason the melting point will be high. since melting point is a measure of the energy required to disrupt the crystal lattice. The molar aqueous solubility can be calculated using melting point of compounds by the general solubility equation." Then melting points affect solubility. and solubility controls toxicity in that: if a compound is only poorly soluble. its concentration in the aqueous environment may be too low for it to exert a toxic effect. ${ }^{5}$ As a result prediction of melting point of the compounds using the proposed non-linear model is a valuable method in designing new drugs within a specified range of melting point and solubility.

\section{Conclusions}

Quantitative-structure property relationships have been applied for prediction of melting point for 323 drug-like conpounds by using the principal component-genetic algorithm-nulti parameter linear regression (PC-GA-MLR) and principal component-genetic algorithm-artificial neural network (PC-GA-ANN) methods. Comparison of the statistical paranteters obtained for training. validation and prediction sets by the PC-GA-MLR and PC-GA-ANN models demonstrate superiority of the PC-GA-ANN model over the PC-GA-MLR model. Root-mean square error of 48.18 for the prediction set by the PC-GA-MLR model should be compared with the value of $12.77^{\circ} \mathrm{C}$ for the PC-GA-ANN model. Since the improvement of the results obtained using non-linear model (PC-GA-ANN) is considerable, it can be concluded that the non-linear characteristics of the principal components on melting point of the compounds is serious.

Acknowledgements. The Authors wish to acknowledge the vice-presidency of research. University of Mohaghegh Ardabili, for financial support of this work.

\section{References}

1. Meylan. W. H.: Howard. P. H.: Boethling. R. S. Emiron. Toricol. Chent 1996. 15. 1000

2. Ran1. Y.: Yalkowsky. S. H. J. Chem. Iff. Conput. Sci. $2001 .+1$. 354.

3. Nimko. J.: Kukikonen, J; Riikonen, K. J. Hazard M Iater $2002,91$. 43 .

4. Dearden. T. C. Sci. Total Emiront. 1991. 109.110.59

5. Katritzky. A. R.: Jain. R.: Lomaka. A.: Petnukhinn. R.: Maran. U.: Karelson. M. Cnst. Growth Des. 2001. 1.261.

6. Godavarthy, S. S.; Robinson, R. L.; Gasem, K. A. M. Ind. Eng. Chem. Res. 2006, 45.5117.

7. Gao. J.: Wang, X.: Yu. X: Li, X: Wang. H. J. Hol Model 2006. 12.521.

8. Krzyzaniak. T. F.: Myrdal. P. B.: Simamora. P.: Yalkowsky. S. H. Ind Eng. Chent Res 1995. 34.2530.

9. Karthikevan, M: Glen, R. C. Bender. A. J. Chem. Inf. Model. 2005. 45,581

10. Toropov, A: Toropova, A.: Ismailov, T; Bonchev, D. $J$. 1 fol. Struct. (Theochem) 1998. 124.237.

11. Firpo. M.: Gavemet. L.: Castro. E. A.: Toropov. A. J. Mol. Struct. (Theochem) 2000. 501-502.419.

12. Toropov, A.; Toropova. A. J. 1 fol. Stuct. Theochem $\mathbf{2 0 0 2}, 581$. 11

13. Yao. X. J.: Wang. Y. W.: Zhang. X. Y.: Zhang. R. S.: Liu. M. C.: Hu. Z. D.: Fant. B. T. Chentont. Intell. Lab. S1st. 2002. 62.217.

14. Consonni. V: Todeschini. R.: Pavan. M.: Gramatica. P. J. Chent Inf. Comput. Sci. 2002. 42.693

15. Karthikevan, M.: Glen. R. C: Bender. A. J. Chem. Inf. Hodel 2005. 45,581

16. Ajmani. S.: Rogers, S. C. Barley. M. H.; Livingstone. D. J. d. Chent. Inf. Hodel 2006. 46.2043.

17. Gramatica. P.: Giani. E.: Papa. E. J. Hol Groph. Hodel 2007. 25. 7556.

18. Todeschini. R. Consonni. V. Hondbook of Molecular Descriptors in Methods and Principles in Hedicinal Chemistry: Mannhold, R: Kubinyi, H: Timmerman. H., Eds; Wiley-VCH: Weinheim. 2000 .

19. Sutter. J. M.: Kalivas. T. H.: Lang. P. M. J. Chenonterr 1992. 6. 217.

20. Malinowski. E. R. Factor Analysis in Chenistry Wiley-Interscience: New York, 2002.

21. Katritzhy, A. R: Tulp, I.; Fara. D. C.: Lauria. A.: Maran, UT: Acree. W. E. J. Chem. Inf. Hodel 2005. 45.913.

22. Hemmateenejad. B.: Akhond. M.: Miri. R.: Shamsipur. M. J. Chem. Inf. Comput Sci. 2003. 43.1328.

23. Hemmateenejad, B.; Shamsipur, M. Intenet Electron. J. Mol Des. 2004. 3,316

24. Jalali-Heravi. M.: Kvani. A. J. Chem Inf. Comput. Sci. 2004, 44. 1328.

25. Hemmateenejad. B.: Safarpour. M. A.: Miri. R.: Nesari. N. J. Chent Inf. Model $2005 .+5.190$.

26. Hemmateenejad, B.; Safarpour, M.; Mir, R.; Taghavi. F. J. Comput. Chem. 2004, 25, 1495 .

27. Depezynski, U, Frost, V. J ; Molt, K. Anal Chim Acta $2000,420$. 217.

28. Hemmateenejad. B. Chentont. Intell. Lab. Stwt 2005. 75. 231

29. Goldberg. D. E. Genetic Algorithm in Search. Optimization and Ifachine Leaning, Addison-Wesley-Longman: Reading, MA. USA, 2000.

30. Cho. S. J.: Hermsmeier. M. A. J. Chem. Inf. Comput. Sci. 2002. 42. 927 .

31. Despagne. F.: Massart. D. L. Anahst 1998. 123. 157

32. Zupan. J.: Gasteiger. J. Netral Networks in Chentistry and Dntg Design: Wilev-VCH: Germany: 1999.

33. Meiler. J; Meusinger. R: Will. M. J. Chem. Inf. Comput. Sci. 2000. 40,1169 
34. Habibi-Yangieh. A.: Nooshyar. M. Phws. Chem. Liq. 2005. 43. 239

35. Habibi-Yangjeh. A.: Nooshyar. M. Bull. Korean Chem. Soc. 2005. 26. 139

36. Habibi-Yangjeh. A.: Danandeh-Jenagharad. M.: Nooshvar. M. Buhl. Korem Chem. Soc, 2005, 26, 2007.

37. Habibi-Yangjeh. A.: Danandeh-Jenagharad. M.: Nooshyar. M. J. Hol. Hodel. 2006. I2.338.

38. Tabaraki. R.: Khayamian. T.: Ensati. A. A. J. Mol. Graph. Model $2006,25,46$

39. Habibi-Yangjeh. A. Phis. Chem. Lia. 2007. 45,471

40. Habibi-Yangjeh. A.: Danandeh-Tenagharad. M. Indian J. Chem. 2007. $46 B .478$

41. Habibi-Yangieh. A. Bull. Korean Chent. Soc. 2007. 28.1472

42. Habibi-Yangjeh. A.: Esmailian. M. Bull. Korean Chent. Soc. 2007. 28. 1477 .

43. Modarresi. H. Dearden, J. C.: Modarress. H. J. Chem. Ihf Model. 2006, 46,930 .
44. HyperChent Release 7: HyperCube. Inc: http: www hyper.com.

45. Todeschini. R. Milano Chemonemics and OSPR (noup): http: www.disat unimib.it vhmn.

46. 11atlab 6.5. Mathworks: 1984-2002.

47. SPSS for Windows. Statistical Package for IBM PC: SPSS Inc: http inww.spss.com

48. Cho. S. J.: Hermsmeier. M. A. J. Chent Inf. Comput. Sci. 2002 42. 927 .

49. Baumant1. K.: Albert. H.: Vonl Korffi. M. J. Chemonem: 2002. 16. 339

50. Lu. Q.: Shen. G.; Yu, R. J. Comput. Chem. 2002, 23.1357.

51. Ahmad. S.: Gromiha. M. M. J. Conput. Chem 2003. 24, 1313.

52. Deeb. O.: Hemmateenejad. B.: Taber. A.: Garduno-Tuarez. R.: Miri. R. Chentosphtere 2007.67.2122

53. Gentic Algorith and Direct Search Toolbor User s Guide: The Mathworks Ine: Massachusetts. 2002.

54. Neural Nenwo Toolbor Liser s Guide; The Mathworks Ine: Massachusetts, 2002 